\title{
Editorial
}

\section{La Universidad y el servicio de la verdad en Centroamérica}

\section{Verdad y Universidad}

Hoy tenemos la tentación de preguntamos, una vez más, como Pilatos frente a Jesús, ¿Qué es la verdad? Quienes más hablan de verdad suelen ser quienes, de alguna manera, la niegan: los grupos fundamentalistas, del signo que sean, los profesionales de los dogmas o los que profesan cualquier tipo de etnocentrismo. Al mismo tiempo, la multidisciplinariedad obligada a la hora de estudiar los temas acluales, la complejidad creciente de los problemas humanos y de la ciencia, las diferentes concepciones filosóficas, antropológicas y hermenéulicas, hacen más difícil hablar de una verdad absoluta. Los diversos marcos culturales de comprensión de la realidad, cuando no los intereses particulares, impulsan de nuevo a preguntarse por la verdad. Esta vez, ya sin el cinismo de Pilatos, podemos volver a interrogamos sobre ella.

Hoy nos mueve a preguntarnos por la verdad no el deseo de escapar a responsabilidades, sino unas veces la confusión ante tanto modo de pensar y de actuar diferente frente a una misma realidad. Otras veces es la misma complejidad de los problemas la que nos conduce a la pregunta. También nos impulsa a ello la resistencia a la charlatanería de quienes quieren convertir la verdad en el reflejo de intereses muy particulares, disfrazados de interés nacional o de le religiosa para ocultar lo antiético de sus propuestas.

La Universidad no puede, en esla siluación, eludir la pregunta por la verdad. Una pregunta que no se puede solucionar de un modo ecléclico, diciendo que unos piensan de una manera y otros de otra. $\mathrm{O}$ afirmando con simpleza que la verdad está en el medio de las afirmaciones contrapuestas. $\mathrm{Ni}$ mucho menos confundiendo verdad con erudición y con puesta al día de los últimos descubri- 
mientos y afirmaciones teóricas. La persona humana, con sus alegrías y sus tristezas, con sus triunfos y sus fracasos, está frente a nosotros y se convierte.en fuente de verdad. Nuestros pueblos crucificados, sus dolores y sus luchas, sus esperanzas y su creatividad están cercanamente presentes en la actualidad y en la historia como fuente permanente de verdad. Verdad que no está en el brillo de una sociedad elitista construída sobre el dolor de muchos, sino en el dolor y en el esfuerzo histórico que los pueblos crucificados hacen por antancarse a sí mismos de sus cruces y construir un mundo más digno. Unirse universitariamente a estas luchas y a estos heróicos esfuerzos constituye la parte medular del servicio de la verdad. Definir el "universitariamente" de esta afirmación será el objetivo prioritario de esta conferencia.

La Universidad nace en sus orígenes con la intención de abrazar la universalidad de los saberes. Se intentaba en ella descifrar y transmitir la totalidad del saber humano. Se procuraba un acercamiento al mundo circundante desde el pensamiento y la incipiente ciencia sin cerrarse a nada y sin permitir que el mundo pequeño de los intereses particulares instrumentalizara el creciente poderío universitario. En una sociedad rígida, esto significó choque, contraste $y$, en ocasiones, persecución tanto para quienes pensaban con libertad como para quienes se abrían al desperlar de una ciencia que golpeaba creencias que habían sido contempladas como columnas de pensamientos establecidos, cuando no oficiales. Los perseguidos fueron muchos. Desde el archicitado caso de Galileo o Miguel Servet, hasta personas como fray Luis de León que se atrevieron a hacer circular sus traducciones direclas al castellano de texlos originales de la Biblia.

Es cierto que la pregunta y que la duda son elementos que hacen crecer el saber y alimentan la búsqueda de la verdad. Es evidente también que la pregunta sincera por la verdad destantea, confunde y con frecuencia irrita, a quienes se consideran poseedores absolutos de la misma. Pero también es cierto que la pregunta debe llevar al compromiso. Pregunta sin acción, pregunta sin búsqueda, pregunta sin hipótesis que pugna por comprobarse en la realidad, sería, parafraseando a S. Pablo, "limbal que suena y címbalo que retiñe".

En este conlexto, en el que la progresiva verdad sobre la persona humana y su entorno se va abriendo camino con dificultades y luchas, con enemigos externos y con estrucluras universitarias internas que frenan y oscurecen la luz de nuevos saberes, las universidades cenlroamericanas no pueden quedarse en la pregunta ni en la duda metódica. Es necesario que la pregunta y la búsqueda de la verdad se convierta entre nosotros en el servicio de la verdad. No puede haber búsqueda de la verdad, o en otras palabras, no puede haber universidad, sin servicio de la verdad. La pregunta en nuestras instituciones no puede ser en nuestros tiempos una pregunta aséplica por la verdad, sino una inquietud ardiente por servir a la verdad desde los medios y plataformas universitarias. 


\section{Verdad desde el Tercer Mundo}

E insistimos en que la Universidad centroamericana tiene que servir a la verdad porque así lo pide la situación en la que vivimos. Nuestras universidades están ubicadas en lo que habitualmente se denomina tercer mundo. En otras palabras en el mundo de los pobres, que son la inmensa mayoría del mundo en que vivimos. Somos parte de ese $\mathbf{8 0 \%}$ de los países del mundo que controlan únicamente el $15.3 \%$ del comercio mundial. Pertenecemos, en una gran mayoría, a esa parte de la familia humana, el $75 \%$ de la misma, que no tiene seguridad económica. La enfermedad, la violencia y la pobreza son, en una alta proporción, contraparte de unas relaciones políticas, económicas y culturales con el mundo rico que piensa más en cómo explotar a nuestros países que en como ayudarles.

La Universidad liene, desde ese marco mundial, que preocuparse por los fenómenos de imperialismo que permanecen iras los procesos de globalización y mundialización. Aunque es evidente que tras estos procesos hay elementos profundamente positivos, y que la conciencia de la comunidd humana ha encontrado en ellos cauces cada vez más adecuados para luchar contra la injusticia en los niveles internacionales, también es cierto que no ha desaparecido la tendencia a ubicar a nuestros países en lugares subalternos y dependientes dentro del marco de la relación entre países. La ayuda internacional al desarrollo no se reparte en relación a los niveles de pobreza de cada país, sino, las más de las veces, según la conveniencia de alianzas y estrategias de los países poderosos. Recordemos para ilustrar lo que decimos que los 10 países con más pobres del mundo tienen 854 millones de personas viviendo en la pobreza (65.9\% de los pobres del mundo según el PNUD, informe de 1994). Sin embargo, estos países recibieron sólo el $31.7 \%$ de la ayuda oficial de los países ricos. Y solo el $43.9 \%$ de los préstamos para el desarrrollo del Banco Mundial.

Si nos fijamos en nuestros países basta con comparar las importantes inversiones y gastos en financiamiento de guerras que Eslados Unidos ha amparado y apoyado entre nosotros, con las exiguas donaciones para la construccción de la paz. Los 5.000 millones de dólares invertidos durante un decenio en El Salvador para financiar la guerra superan en exceso a los exiguos planes de ayuda que la resconstrucción del país y el financiamiento de la paz ameritarían. Los ejemplos de la desproporcionada ayuda militar a Honduras y el financiamiento de la guerra civil en Nicaragua no hacen más que abonar lo que decimos.

La globalización, empero, juega a favor de la democratización. Porque no puede haber globalización real sin socialización de avances tecnológicos, sin universalización de una comunicación rápida y eficiente, sin inmediatez y apertura de información. Ello constituye al mismo tiempo que una esperanza, un reto para nuestras universidades, con frecuencia tan centradas en sí mismas y tan olvidadas de su vocación universalista. El universalismo es el concepto contra- 
puesto al imperialismo, y la globlización, aunque con frecuencia es utilizada al servicio del imperialismo, lleva consigo unos gérmenes de universalidad que son, si se saben utilizar, más poderosos a largo plazo que las tendencias manipuladoras que los intereses particulares, corporativos o nacionales, incrustan en los movimientos de naturaleza universal.

Con el fin de las luchas ideológicas ha crecido también la idea de que no debe utilizarse un lenguaje desgastado por el abuso ideologizado que se ha hecho del mismo en el pasado reciente. Sin embargo, el fenómeno del imperialismo está hoy tan vigente o más que en los años de la guerra fría. Con el agravante de que quienes nos explotan ligan toda denuncia contra su explotación con regimenes o ideologías históricamente fracasadas. $Y$ con el agravante también de que nosolros caemos fácilmente en esta trampa.

Así, una institución universitaria que en el tercer mundo renunciara a ser antiimperialista, por conveniencia, temor o moda intelectual, no podría ser considerada universidad en el sentido original de institución que trata de abarcar y comprender la realidad en su universalidad. Y en Centroamérica, en concreto, estaríamos además renunciando tanto a la dignidad de antepasados que resistieron la imposición colonial, como a las semillas de antiimperialismo que personas como Las Casas comenzaron a plantar en la conciencia mundial después de contemplar los desmanes cometidos en nuestras tierras de parte de los conquistadores. En otras palabras, estaríamos renunciando a lo mejor de nuestra historia.

Con todo, no se trata de adoplar una actitud exclusivamente de denuncia. Como decíamos anteriormente, la conciencia de la humanidad, y con ella las instiluciones internacionales, han crecido en comprensión de la situación mundial. Los grupos solidarios se multiplican en el primer mundo y las instituciones mundiales están abiertas, y algunas plenamente comprometidas, con los esfuerzos de justicia de nuestros pueblos. En este contexto la Universidad debe buscar y aportar soluciones a los problemas candentes que nos rodean. Es así mismo evidente que dentro de una posición claramente antiimperialista caben estrategias diversas, pasos matizados y negociaciones que hagan avanzar de un modo realista nuestro caminar hacia el desarrollo y la construcción de un estado de derecho que borre toda sombra de república bananera. La investigación, la docencia y la proyección social son áreas privilegiadas en la búsqueda y propuesta de soluciones.

\section{Servicio de la verdad en Centroamérica}

Y entramos así en otro aspecto fundamental del servicio de la verdad. Debe este servicio no solo estar enmarcado en el contexto mundial, sino también en el contexto centroamericano. Desde su independencia y su casi inmediata desmembracion en cinco países, nuestro istmo ha guardado la nostalgia de una 
Centroamérica unida. En la aclualidad la realidad socioeconómica, que afirma clara y duramente que nuestros países no tienen solución de fuluro sin una integración regional, ha llevado a dar límidos pasos en esa dirección. Sin embargo, y con lo avanzado, los seis sellos y dos firmas que deben estamparse en un papelito que después se tira, para pasar la frontera de Honduras cuando se viaja en carro particular, permanece como símbolo de las tan inmensas como estúpidas trabas que quedan todavía por superar. Semejanle mezcla de burocracia, inulilidad y despilfarro de recursos en salarios inútiles se da en lodas las fronteras del área, convirtiéndolas en signo permanente de división en vez del lugar que debería ser de encuentro y de abrazo fraterno.

Investigación, docencia y proyección social son indispensables en nuestras universidades, pero entendidas en el ámbito centroamericano. Por supuesto que cada país debe ponerse sus melas y debe mirar hacia sí mismo. Pero si nos falta la capacidad de abrir nuestro trabajo a la complejidad y extensión centroamericana, estaremos traicionando una vez más, y más gravemente todavía, la esencial dimensión universitaria de la universalidad. Porque esta universalidad se construye siempre desde lo cercano hacia lo lejano, desde lo que da conciencia de sí hacia lo que da conciencia de la pluralidad y el universalismo. Ser centroamericano y ser latinoamericano, es, de esa manera, paso indispensable para realizar la función universitaria en su dimensión integral.

\section{a) La Investigación}

La investigación es indispensable en países como los nuestros que, podemos decirlo, se conocen a sí mismos escasamente, tanto en su dimensión físico material como en su dimensión sociohistórica. Nuestras universidades, y me refiero ahora a las dos UCAs han desarrollado, o están desarrollando, investigaciones que son señeras y ejemplo claro de la importancia de un estudio serio de la realidad físico material. La UCA de Managua, con su investigación sobre la energía solar y la elaboración de un mapa solar de Nicaragua ha posibilitado que este país lleve una enorme ventaja en este terreno a los demás del área, y facilita una pronta aplicación de la tecnología de aprovechamiento de esta fuente de energía. Para un país pobre, pero lleno de sol, como Nicaragua, el conocerse científicamente a sí mismo en sus recursos es indispensable para salir de la pobreza.

La UCA de El Salvador, por su parte, está desarrollando un estudio sobre la aceleración de la tierra durante los terremotos que posibilitará códigos de construcción basados en el propio modo de temblar la tierra salvadoreña en vez de copiarlos de otros países donde también se dan fenómenos sísmicos pero donde la aceleración de la tierra es distinta. Tanto para salvar vidas como para proteger inversiones materiales este estudio es indispensable. 
Resulta casi escandaloso que nuestros países no se conozcan a sí mismos en aspectos tan elementales como lo son los que constituyen su propia configuración física. Pero la pobreza de las mayorías y el afán de enriquecimiento de unas minorías profundamente egoíslas y cortas, se han constituído en freno difícil de superar para una investigación seria y que alcance las raices de nuestra realidad físico-material. La formación de una nueva generación de profesionales caería por su propia base si nuestras universidades, $y$ hablo ahora de la universidad en general, descuidan esta dimensión investigativa que lleva a conocer en profundidad la propia realidad material. Hablar de desarrollo sin esta base material de autoconocimiento no solo es absurdo sino ridículo.

La dimensión sociohistórica es también un campo indispensable para la investigación. Solo desde el conocimiento serio del rejuego en las relaciones humanas de nuestros pequeños países podremos construir un futuro democrático y un estado de derecho. La escasez de estudios sistemáticos y continuados en campos tan cotidianos como la problemática familiar, la violencia, el alcoholismo, las concepciones políticas, la corrupción administrativa y un largo etc., es una realidad que clama al cielo. La incapacidad demostrada hasta el presente por las universidades para iniciar juntas y coordinar en estos terrenos estudios comparativos que abarquen la globalidad centroamericana, es síntoma claro de nuesIras deficiencias en el campo de la investigación.

La investigación debe también preocuparse por el tipo de desartollo que deseamos, por las posibilidades del mismo y por el discurso que se maneja al respecto. Cuando uno recorre la historia de nuestros países descubre que hace un siglo, con excepciones tan dignas como la de Rubén Dario en Nicaragua, se dedicaban loas interminables al progreso. El ferrocarril era el gran símbolo y la inversión extranjera la vara mágica que incorporaría nuestros países a un futuro maravilloso. En la feria de Nueva York de pricipios de este siglo un general hondureño ensalzaba las posibilidades de inversión que dicho país presentaba. Incluso las guerras civiles, que eran parte de la tradición nacional en ese momento, servirían, según el general, al desartollo de la inversión extranjera. Los bandos en pugna, decía, mientras castigaban al comerciante nacional por alinearse con cualquiera de las partes, no se atreverían a molestar a los extranjeros por el afán de ganarse su benevolencia. Todos sabemos a dónde condujo este delirio de fe en el desarrollo ilimitado y en la inversión extranjera. La actual pobreza y las guerras y atrocidades de la década de los $\mathbf{8 0}$ fueron trágico colofŏn a la ingenuidad.

Mientras hoy se nos vuelven a repetir cantos de sirena sobre el futuro desarrollo de nuestros pueblos, las universidades tienen que visualizar una sociedad que combine el desarrollo sostenido con la austeridad y la solidaridad. Los modelos de desarrollo de los países ricos no son universalizables. Ni siquiera son sostenibles en un mundo que quiera ser mínimamente justo. El desarrollo actual 
de Estados Unidos nos puede servir como ejemplo: En este país vive el $6 \%$ de la humanidad, manteniendo unos niveles de consumo significativamente altos, que son a su vez, uno de los baremos con los que se acostumbra a medir el desarroIlo. Pues bien, si este nivel de consumo se quisiera extender a lodo el mundo habria que aumentar en más de cinco veces la producción mundial. Pues en la actualidad, con la oferta actual de recursos existentes en la tierra, el nivel de consumo norteamericano solo podría extenderse al $18 \%$ de la humanidad. Y en ese caso, el resto de la humanidad quedaría sin ninguna oferta de consumo.

La investigación económica y en el campo del desarrollo es indispensable para que no se repita no ya la década perdida, sino lo que si fuéramos pesimistas podríamos definir como la centuria perdida. Porque salvadas las naturales diferencias, ¿viven mejor hoy las mayorías populares de lo que vivían las mismas mayorías hace 100 años? En los días inmediatos a la independencia de la India se le preguntó a Gandhi si por fin su país, independiente, conseguiría los niveles de desarollo y bienestar de Inglaterra. La respuesta de Gandhi no se hizo esperar: "Inglaterra necesitó explotar a $2 / 3$ de la humanidad para lograr su nivel de desarrollo ¿Cuántos mundos creen Uds. que necesitaría la India?”

Nuestros países deben buscar el desarrollo, pero el camino seguido por las potencias imperiales del pasado y el presente no es repetible. Como no es repetible el derroche de los países ricos que ha llevado a la escandalosa realidad de que las 358 personas más ricas del mundo tengan un patrimonio superior al ingreso anual del $45 \%$ de la humanidad (más de 2.000 millones de personas). Solo una investigación de modelos adecuados de desarrollo basados en la ausleridad y la solidaridad pueden ofrecer esperanza a nuestros países. En esta búsqueda de nuevos modelos la Universidad debe mantener undiálogo permanente tanto con gobiemos, insitituciones políticas, organizaciones populares y empresa privada. Con esta última el diálogo es especialmente urgente por el peso real que tiene en la configuración de los modelos de desarrollo y por la poca importancia que tradicionalmenle había dado (se comienzan a observar algunos cambios positivos en la aclualidad) a una investigación seria.

Se dice que la investigación es cara y que las instituciones internacionales de ayuda, incluídos los gobiemos, están más interesados en proyectos cortoplacistas que en estudios de menor brillantez inmediata pero que a largo plazo son fundamento indispensable de eficacia para cualquier tipo de planificación del futuro. Pero también hay que reconocer que nuestras universidades se han dejado llevar, con frecuencia, del interés farisaico que se nos impone desde fuera y se han apuntado exclusivamente a proyectos coyunturales de invesligación, cuando no a obras concretas de desarrollo que corren el peligro de distraer de lo que son funciones propiamente universitarias. 


\section{b) La docencia}

La docencia, aunque le dedicaremos menor espacio en nuestra reflexión, en parte porque tenemos mejor asimilada su importancia, es otra área indispensable del servicio de la verdad. Al servicio de la apertura intelectual, del desarrollo de hábitos científicos en los procesos de acercamiento cognoscitivo a la realidad, de la creación de criterio ético y de libertad personal frente a las posibilidades que la realidad ofrece, la docencia no puede ser autoritaria ni caer exclusivamente en métodos de enseñanza bancario-acumulativa. La participación del alumno en su propia formación, el desarrollo de mecanismos de diálogo, la voz y la creatividad del alumno son parte indispensable de la docencia.

Frente a versiones legalistas de la verdad la docencia debe ligar la verdad con la libertad humana. Frente al seudorealismo de la innumerable gama de oportunistas que pueblan nuestros países (verdad es lo que funciona, nos dicen), la docencia debe priorizar lo ético frenle a unos hábitos y coslumbres tantas veces corruptos y corruptores. Frente al desinterés del más o menos, los docentes deben transmitir el gusto y el afán por la exactitud y rigurosidad científica. Frente a las afirmaciones míticas o gloriosistas de nuetra identidad cultural, el universitario debe aportar una cultura en la que el trabajo, la responsabilidad y la permanente y progresiva construcción de una sociedad en proceso de humanización sean las claves de autoevaluación histórico-social.

La docencia no es solo el momento de transmisión de conocimientos sino, sobre todo, el lugar en el que se contagian actitudes cientificas y humanistas. La elaboración de planes de estudio conjuntos a nivel centroamericano, la posibilidad de intercambio de profesores, el impulso de participación centroamericana en seminarios de parte de nuestros alumnos, son temas urgentes que no pueden posponerse. Los pasos iniciales del CSUCA son ciertamente encomiables, pero tienen que ser vistos más como estímulo y punto de partida que como meta ya realizada.

Aunque la responsabilidad es de toda la Universidad, la docencia tiene que preguntarse también a quién está sirviendo. Mélodos autorilarios de enseñanza acaban sirviendo a sociedades autoritarias. Métodos aburridos y poco creativos servirán sin duda a la perpetuación de la voraz burocracia estatal, siempre ávida de engrosar sus filas de personajes aburridos, malhumorados y rílmicamente repetitivos de los mismos inútiles Irámiles. Métodos que privilegien el trabajo individual e incluso insolidario, darán dignos descendientes a los profesionales que ponen por encima de cualquier otro valor el éxito y la fortuna personal. Profesores poseídos por el orgullo y la soberbia de sus lítulos, darán alas al elitismo, agravando el problema de estas sociedades nuestras que protegen y amparan a las élites mientras olvidan a las mayorías empobrecidas. Sistemas racionalistas y pragmáticos de educación, que ahoguen el sentimiento y la creatividad artística en beneficio de intereses exclusivamente materiales y concretos, 
generarán profesionales incapaces de valorar humana, e incluso cristianamente, la realidad. Solo atravesando el abismo que separa la concepción de la verdad como poder de la concepción de la verdad como servicio, se inicia el proceso de una docencia liberadora.

La Universidad tiene que preguntarse siempre a quién y a qué está sirviendo. $Y$ si somos mínimamente autocríticos veremos que hasta el presente la Universidad, en su conjunto, ha servido en Centroamérica más a la perpetuación de sistemas opresivos e injustos que al crecimiento en desarrollo económico y social o a la democratización y afianzamiento del estado de derecho. Es evidente que se han hecho cosas buenas y que no hay que desanimarse ante los errores y fallos del pasado ( $y$ del presente, tal vez podríamos decir). Pero también hay que reconocer con humildad que el peso del producto universitario, medido a traves de sus profesionales egresados, bascula todavía mayoritariamente en favor del mantenimiento del "statu quo". La docencia, desde una mejor preparación académica, desde una renovación de sus métodos, desde una mayor comunicación y coordinación con el mundo universitario centro y latinoamericano, puede y debe jugar un papel preponderante en el cambio de mentalidad de nuestros egresados.

Finalmente, la docencia debe fomentar en el alumno la capacidad de estudio, reflexión e investigación multidisciplinar. Los problemas son cada vez más complejos y la época en que se podía pensar que las soluciones dependían de un solo especialista han quedado sepultadas en el pasado. Hoy el acercamiento serio a la verdad exige ópticas y planos diferentes de observación de la realidad que sólo pueden lograrse desde un diálogo permanente entre las ciencias y las personas.

\section{c) Proyección Social}

La proyección social resume y unifica investigación y docencia. Toda universidad tiene, de hecho, una posición y una influencia en la sociedad en la que funciona. La proyección social es la toma de conciencia de la propia Universidad sobre su papel en la sociedad, y la disposición a plasmat, a través de publicaciones y declaraciones, su opinión sobre el entorno social en el que se desenvuelve. Palabra que pretende ser transformadora y volcar el peso de la institución en favor del necesario cambio social y de la toma de conciencia que lo posibilita. Ignacio Ellacuría decía sistemáticamente que la primera asignatura de la Universidad era la realidad nacional. La proyección social es la palabra pública que la universidad, en cuanto tal, dice, después de haber estudiado esa primera asignatura de la vida universitaria.

En sociedades conflictivas como la nuestra esa tarea no es fácil. La UCA de El Salvador, y en ella la vida universitaria centroamericana, tiene sus mártires explícilos, y con connolación universal, que fueron asesinados por ser coherentes con la tarea universitaria de poner racionalidad en una realidad sociopolítica 
dominada por el enfrentamiento y la brutalidad. Otras universidades tienen también sus mártires, caídos en luchas contra dictaduras como la somocista o contra regímenes sanguinarios como los últimos gobiemos militares de Guatemala. Por ello la tarea de poner racionalidad en nuestras sociedades sigue presente como reto para nosotros y como esperanza para nuestros pueblos.

Hoy, la Proyección Social sigue teniendo una función múltiple y necesaria para incidir en nuestras sociedades. La Proyección Social debe contribuir a poner al descubierto las potencialidades de nuestros pueblos. Las capacidades artíslicas, la creatividad en el ámbito de la cultura, son terreno propio de la proyección social. Una universidad en la que el estudiante no puede expresar el sentido poético de la vida de su pueblo, tamizado por la propia experiencia y sensibilidad, a través del teatro, la música, la danza o cualquier otro medio de expresión artística, es una universidad chata, y su comunicación con la sociedad en la que vive demasiado discursiva y abstracta.

La difusión de información y reflexión seria sobre la realidad es también parte indispensable de la proyección social y contribuye a esa autoconciencia que todo país que aspire al desarrollo debe tener. En este contexto, la proyección social debe estar muy unida a la investigación y a la docencia. Es esta función universitaria la que debe socializar los frutos de la investigación físico-material o socio-histórica, la que debe extraer consecuencias para nuestras sociedades y la que debe impulsar la reflexión social desde los datos obtenidos y desde el conocimiento acucioso de la realidad. Así mismo, debe ligar la docencia con esta tarea diaria de pensar y convertir la realidad de nuestros países centroamericanos, latinoamericanos y ubicados en el Tercer Mundo, en la primera materia de estudio universitario.

La denuncia de todo lo que deshumaniza a nuestros conciudadanos y sociedades es así mismo tarea de proyección social. En nuestros países concrelos sufrimos las plagas incesantes de este sistema en el que ricos cada vez más ricos progresan a costa de pobres cada vez más pobres. Quienes estudian el reparto de la riqueza a nivel mundial nos informan coincidentemente que en 1960 el $20 \%$ más pobre de la humanidad se repartía el $2.3 \%$ de la renta mundial. En 1980 la porción de la renta mundial para este mismo grupo había descendido al $1.7 \%$. Y en 1990 al $1.4 \%$. Al mismo tiempo el $20 \%$ más rico de la humanidad se repartía en 1960 el $70.2 \%$ de la renta mundial, en 1980 el $76.3 \%$, y en 1990 el $82.7 \%$. Dicho en palabras del PNUD (1994), en 1960 el 20\% más rico de la población mundial registraba unos ingresos 30 veces más elevados que el $20 \%$ más pobre, mientras que en 1991 el mismo $20 \%$ más rico recibía unos ingresos 61 veces mayor que el $20 \%$ empobrecido. En la medida en que esta situación se repite en nuestros países la Universidad no puede permanecer callada.

Pero no se trata solo de denunciar al ídolo de la riqueza como engranaje clave de la configuración social en nuestra región. Hay que analizar también, 
una por una, todas aquellas instituciones y modos de acluar que frenen u obstaculicen el desarrollo y la dignidad humana. Por poner un simple ejemplo, y aunque nuestros ejércitos ya han sufrido una primera reducción en sus inflados presupuestos, es casi increible lo que se puede hacer de cara a luchar contra el analfabelismo, reducir la mortalidad infantil o potabilizar el agua de las personas que carecen de este servicio, simplemente trasladando un 12 o un $15 \%$ de los presupuestos anuales militares a actividades de atención primaria de salud o desarrollo social. Hacer propuestas que pongan racionalidad, y con ello verdad, en los niveles de injusticia de nuestros sociedades es parte de la tarea de la proyección social o, como otros la llaman, la extensión universitaria. Racionalidad y propuesta que debe extenderse a todos los campos del entramado social de un modo solidario y preocupado preferencialmente por los más golpeados, marginados u oprimidos de nuestrs sociedades. Las minorías, la marginación de la mujer, el olvido y menosprecio del mundo indígena, son problemas que la universidad debe enfrentar si quiere tener una palabra auténtica y coherente. Sin opción preferencial por los despojados de nuestras tierras la capacidad propositiva de la universidad y la incidencia que debe tenerse en las estructuras políticas y sociales, quedaría profundamente debilitada $y$, con toda seguridad, insabora y descafeinada.

Nueiros países carecen de una desarrollada conciencia histórica, y especialmente en los últimos años han sufrido auténticas campañas de desinformacion sobre la propia realidad nacional. Nuestras guerras civiles han sido leídas con demasiado énfasis en la ideología, y las atrocidades han quedado, en ocasiones, disimuladas o subrayadas según los intereses políticos particulares. La proyección social tiene aquí una ingente tarea a la hora de reconstruir una conciencia histórica desde la verdad que posibilite la no repetición de los errores del pasado. Y tiene también la ingente tarea de que al menos ante la historia y ante la verdad no queden impunes los responsables de crímenes de lesa humanidad. Crímenes que con tanta facilidad y con tanto desprecio de la vida se han cometido en nuestros pasados inmediatos.

Hoy se habla con relativa frecuencia de elaborar proyeclos de nación. Se parte, a la hora de proponerse esta tarea, de un hecho muy simple. Nuestros países no tienen una idea clara de cómo quieren construir su propio futuro. Los intereses particulares privan con frecuencia sobre los intereses colectivos, generando arbilrariedad, contradicciones y campos protegidos de impunidad y corrupción. Los partidos políticos mienten dibujando, a base de promesas, un futuro que nunca llegará, en gran parte porque no está bien diseñado en sus condiciones de posibilidad. El hacer un proyecto de nación estimularía la reflexión sobre lo que queremos de nuestros países y pondría metas colectivas y justas de desarrollo.

Debajo de este tipo de propuesta puede estar agazapada la idea de un proyec- 
to único y absoluto de nación, reñido con el indispensable pluralismo que se necesita para construir la democracia. La universidad no debe por ello ponerse como meta la elaboración de un proyecto de nación particular. Pero sí establecer una agenda de discusión en torno a los problemas nacionales y regionales que pueda servir como base para proyectos políticos y sociales de nación. La proyección social universilaria debe jugar en ese campo, simultáneamente, el papel de catalizador y de conciencia crítica. El desarrollo de mediciones de la opinión pública puede jugar, en este contexto, un importante papel para contrastar proyectos de nación, programas políticos, etc. Y también para medir la incidencia de la constelación de valores que o bien posibilita el desarrollo o bien deforma la conciencia de nuestros pueblos.

\section{Reflexiones finales}

El trabajo universitario, lo decíamos al principio, liene como objetivo fundamental que la vida en nuestra región sea más humana y por tanto más digna. No se Irata de hacerlo todo, pero sí de poner las premisas para una construcción del futuro que tenga prioritariamente en cuenta a las grandes mayorías empobrecidas de nuestros países. Ello implica que el servicio a la verdad de la universidad deberá apoyar sistemáticamente a aquellos grupos humanos que se organicen a sí mismos, hacia dentro y hacia fuera de ellos, en base a valores de solidaridad. La misma universidad debe ser profundamente autocrítica y tralar de organizarse como una comunidad de solidaridad, tanto en su estructura interna como en su proyección hacia la sociedad.

El equilibrio entre la globalidad y las particularidades, la conciencia ecológica, el trabajo constante en la reforma de toda estructura social discriminatoria, el diseño de una sociedad en la que se combinen desarrollo, justicia y austeridad son parte indispensable del servicio a la verdad. Esa verdad que nos hace libres en la media en que es concreta, cienlífica, humana y humanizadora.

Nos gusta hablar, en este fin de siglo, del nuevo milenio. Aunque los festejos serán inevitables y la fraseología nos retrotraerá de nuevo a épocas barrocas, la sociedad del siglo XX está demasiado desengañada como para tomarse en serio ideas milenaristas. Frente a esa oportunidad que toda fecha ofrece para la reflexión, la humanidad encontrará dos alternativas: reconocer la gravedad de los problemas que hoy nos aquejan, mundiales y regionales, y ponerse a planificar y a dar los pasos pertinentes de solución, o sumarse simplemente a la dinámica de los fuegos artificiales que sin duda alumbrarán las 00 horas del 1 de Enero del año 2.000 en muchas capitales del mundo. La palabrería, como los fuegos de artificio, no hará más que encender en nuestra noche una falsa aurora. Con el agravante de que a los fuegos vamos simplemente con el deseo de pasar un buen rato sabiendo que la noche sigue su curso. Las falsas auroras, al contrario, siempre crean graves decepciones. 
El problema del tercer milenio no se resuelve con frases y exhortaciones que mezclan el voluntarismo con el idealismo, sino encarando rigurosamente la problemática con la que termina el segundo milenio.

La generación del año 2.000 tendrá capacidad para resolver sus problemas en la medida en que nuestras universidades, entre otras instituciones, afronten con seriedad la problemática en que vivimos. En particular las universidades, como poderosas plataformas que pueden ponerse al servicio de la verdad, tienen una grave responsabilidad en la articulación del futuro centroamericano.

La generación del año 2.000 tendrá liderazgo en la necesaria transformación de nuestros países si desde hoy nosotros nos comprometemos con renovada energía con la justicia, con la paz y con un desarrollo construído sobre el aprovechamiento racional de los recursos, la solidaridad y la austeridad. Sin el servicio universitario de la verdad esla tarea será hoy poco menos que imposible.

José María Tojeira, SJ. 